\title{
Current Use of Chromosomal Microarray by Australian Paediatricians and Implications for the Implementation of Next Generation Sequencing
}

Victoria McKay ${ }^{1}$, Daryl Efron ${ }^{1,2,6}$, Elizabeth E. Palmer ${ }^{3,4,5}$, Susan M. White ${ }^{2,6}$, Chris Pearson ${ }^{7}$ and Margie Danchin ${ }^{1,2,6}$

1. Department of General Medicine, Royal Children's Hospital, Parkville VIC 3052, Australia

2. Murdoch Children's Research Institute, Parkville VIC 3052, Australia

3. Sydney Children's Hospital, Randwick, NSW 2031, Australia

4. Department of Women and Children's Health, Randwick Campus, University of New South Wales, NSW 2031, Australia

5. Genetics of Learning Disability Service, Waratah, NSW 2298, Australia

6. Department of Paediatrics, University of Melbourne, Australia

7. Department of General Medicine, Women's and Children's Hospital, North Adelaide SA 5006, Australia

Corresponding author:

Dr Victoria McKay

Department of General Medicine

Royal Children's Hospital

Flemington Road, Parkville, Vic. 3052, Australia.

Email: Victoria.mckay@,rch.org.au

Word Count (main text):

2496

This is the author manuscript accepted for publication and has undergone full peer review but has not been through the copyediting, typesetting, pagination and proofreading process, which

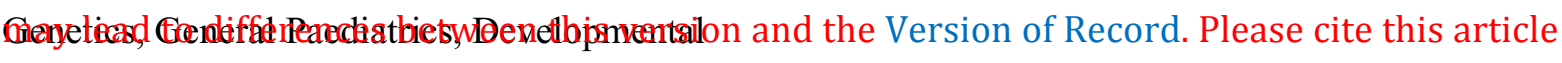
as doi: 10.1111/jpc.13523

This article is protected by copyright. All rights reserved. 


\section{Acknowledgements}

We would like to acknowledge the APRN members who participated in this study,

Dr Jane Lesslie and Dr Heidi Webster for their involvement in the formulation of the survey, and the Department of Medical Genetics, Sydney Children's Hospital, in particular Dr David Mowat, Dr Carolyn Shalhoub and Dr Rani Sachdev, for allowing us to draw from their CMA resources and guidelines.

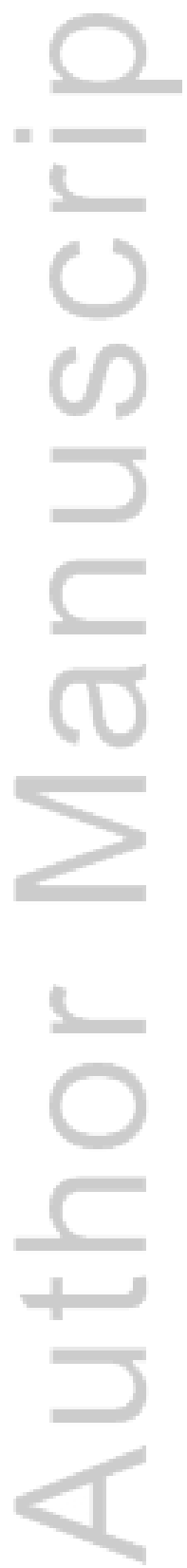

This article is protected by copyright. All rights reserved. 


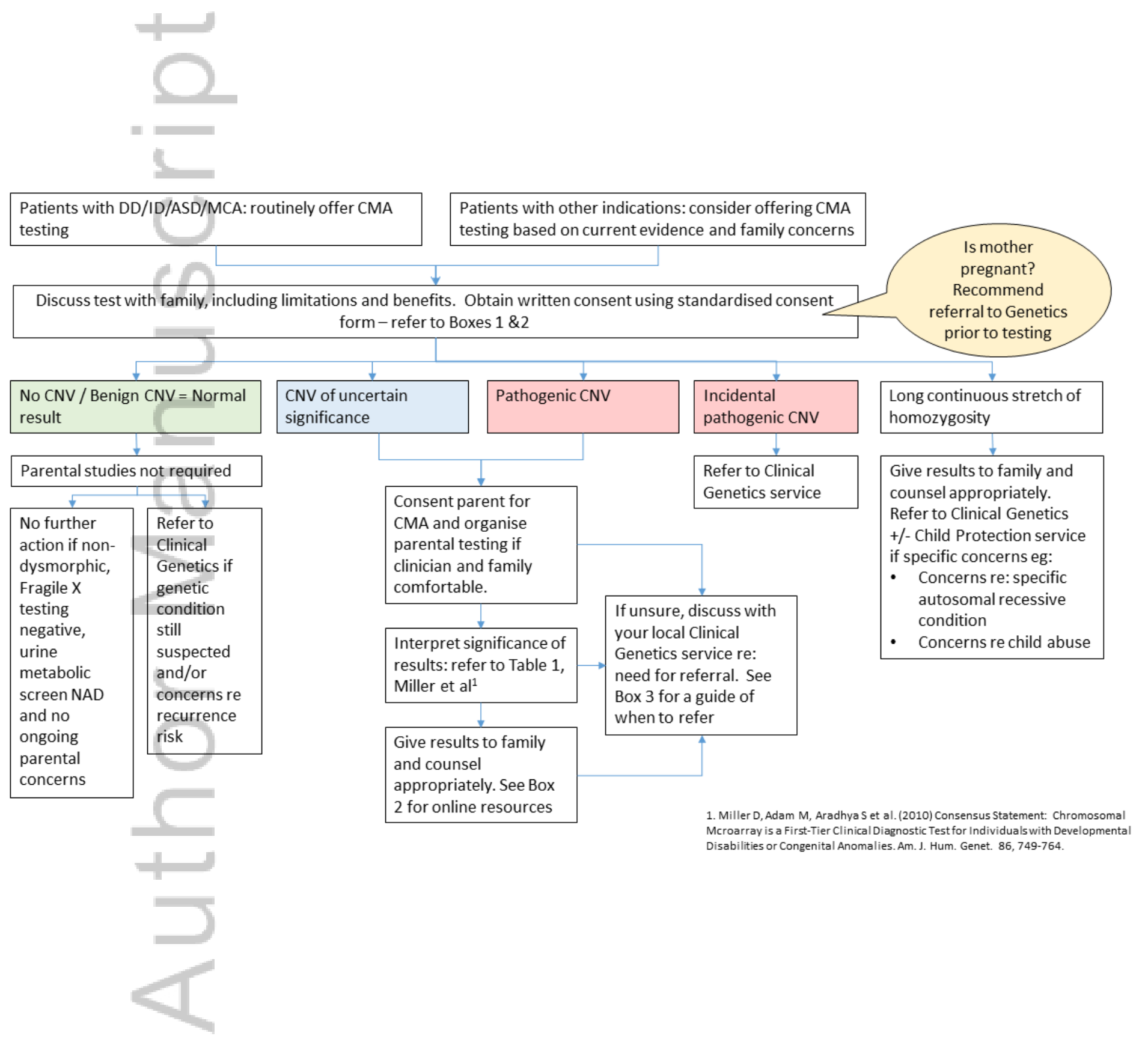

This article is protected by copyright. All rights reserved. 


\section{ABSTRACT}

Aims: Chromosomal microarray (CMA) is an important diagnostic test for children with multiple congenital anomalies or certain developmental behavioural problems suggestive of an underlying genetic diagnosis. However, there are medical and ethical complexities to its use and few Australian policies to guide practice. We aimed to describe the current practice of Australian paediatricians in relation to CMA testing. We hypothesised that there are knowledge gaps in their use of CMA.

Methods: Online survey completed between September 2015 and January 2016 by paediatricians in secondary care settings. Participants were members of the Australian Paediatric Research Network. One-hundred and sixty five (43\%) of 383 active members responded. Our main outcome measures comprised: (i) the indications for which paediatricians request CMA; ii) their approach to consent; (iii) their interpretation of results; and (iv) their understanding of the impact on patient management.

Results: A significant proportion of paediatricians (21-52\%) did not regularly use CMA for conditions with established evidence of diagnostic yield. Paediatricians under-estimated the potential for CMA findings to alter patient management. There was wide variability in paediatricians' approach to consent, and low use of consent forms and fact sheets. Paediatricians reported difficulties interpreting CMA results, with high rates of referral to clinical genetics services.

Conclusions: The reported practice of Australian paediatricians is not consistent with international standards on CMA. Australian practice could be improved by a standardised approach to ordering CMA, consenting patients, and interpreting results. We provide resources for CMA ordering and make recommendations about preparation for Next Generation Sequencing.

\section{What is already known on this topic:}

1. Chromosomal microarray (CMA) is a recommended investigation for developmental delay, intellectual disability, autism spectrum disorder and multiple congenital anomalies.

2. CMA testing potentially has complex implications for patients and their families.

3. Next Generation Sequencing (NGS) is likely to introduce even more complexities.

\section{What this paper adds:}

1. In this survey of Australian paediatricians' use of CMA testing, reported practice was not consistent with international standards.

2. A standardised approach to CMA use, patient consent and referral to clinical genetics would improve paediatric practice.

3. These methods can be extrapolated to address the challenges of NGS. 


\section{INTRODUCTION}

Genetic medicine is a rapidly evolving field, which is improving the diagnosis and management of patients with chromosomal and Mendelian conditions. In recent years, Chromosomal Microarray (CMA) testing has become a mainstream genetic investigation. In the 2015-2016 financial year, 14,602 requests for CMA were processed under the Medicare Benefits Scheme. ${ }^{1}$ However, it is not known how CMA testing is used in Australian paediatric practice.

CMA is recommended as a first-line investigation for autism spectrum disorder, developmental delay, intellectual disability and multiple congenital anomalies. ${ }^{2}$ For these indications, CMA has a diagnostic yield of $10-20 \%,{ }^{23,43,54}$ compared to approximately $3 \%$ using conventional cytogenetics ${ }^{36}$, and carries a Medicare rebate (Item number 73292). For a number of other conditions (eg epilepsy, cerebral palsy, single congenital malformations, and short stature) CMA has a diagnostic yield between $6-20 \%{ }^{47}$

CMA testing identifies sub-microscopic deletions and duplications in the genome, termed Copy Number Variants. The significance of a CNV is determined by literature search, comparison with databases cataloguing CNVs and phenotypes, and by segregation studies in the family. CNVs are then classified as pathogenic, benign, of uncertain significance or of unknown significance. ${ }^{5,68,9}$ Interpretation and terminology can differ between laboratories. ${ }^{7,810,11}$ The interpretation of the pathogenicity of a CNV is subject to revision as databases of genotype and phenotype expand. ${ }^{312}$

There are many ethical, legal, medical and service-provision issues related to CMA testing. Results of uncertain or unknown significance can be particularly challenging for clinicians to interpret and manage. CMA testing may identify incidental findings in patients and their relatives; these may infer risk for adult-onset conditions. Finally, CMA testing may reveal, non-paternity or non-maternity, or, if a SNP based array platform is used, parental consanguinity, non-paternity or non-maternity. Comprehensive pre- and post-test counselling is therefore recommended, which is often timeconsuming.

With the impending introduction of Next Generation Sequencing (NGS) into diagnostic practice these issues will be amplified. Next Generation Sequencing involves high-throughput sequencing in a single experiment, allowing the analysis of sequence variation of multiple genes in parallel. It can be used to sequence a number of genes relevant to a particular condition (gene panel), capture the exons (coding regions) of all genes (exome sequencing) or capture the whole genome (genome sequencing). ${ }^{913}$ While Next Generation Sequencing has unprecedented potential as a screening and diagnostic tool, it will also generate considerable challenges for clinicians, health services, and families. With each new technology comes implementation challenges, including upskilling of nongenetic healthcare providers in pre- and post-test counselling, interpreting results, and developing and using information materials and consent forms. The introduction and use of CMA testing has 
provided a model for anticipating and preparing for the likely issues that will arise with Next Generation Sequencing. ${ }^{814}$

With this is mind, we surveyed Australian paediatricians aiming to describe their current practice in relation to CMA testing including: (i) the diagnoses for which CMA is requested; ii) the consent process; (iii) interpretation and use of results; and (iv) paediatricians' understanding of how CMA results impact on patient management. We hypothesised that although CMA is frequently requested by paediatricians, there are knowledge gaps in the interpretation and application of results. We compared our findings to current standards of practice to highlight paediatricians' needs for further training and support in the use of CMA. We make 'Best Practice' recommendations regarding CMA consent and cite resources which can be used to guide use of CMA in children. These findings and resources will help to inform the likely needs of doctors as Next Generation Sequencing is introduced into clinical care.

\section{METHODS}

\section{Design, Setting and Participants}

The Australian Paediatric Research Network (APRN) facilitates multi-site research in secondary care paediatric settings. ${ }^{150}$ All Australian states and territories are represented. In 2015, the APRN consisted of 486 members, of whom 383 were active (participated in an APRN study in the last five years since 2010) and 103 inactive.

Between September 2015 and January 2016, APRN members were invited to complete the 2015 Multi-Topic Survey (MTS). Prior to circulation, the survey was piloted with 10 general paediatricians; changes were made to ensure readability and ease of completion. The survey was emailed to APRN members and completed online via Research Electronic Data Capture, a secure online data capture service. ${ }^{161}$ Three reminders were sent between October 2015 and January 2016. Ethics approval was obtained by The Royal Children's Hospital Melbourne Human Research Ethics Committee (HREC number: 35142).

The 2015 MTS consisted of three sections. The CMA section consisted of 12 questions. Paediatricians reported on their practice over the past year. The questions used a four part Likert scale, with response frequency categorised as "Rarely < 10\%"; "Sometimes 10-50\%", "Frequently 5190\%" and "Almost Always $>90 \%$ ". Responses were analysed by grouping "Rarely" with "Sometimes" (0-50\%), and "Frequently" with "Almost Always" (51-100\%). Some questions permitted selection of more than one answer.

\section{Survey Content}


The survey questions were designed by the study authors (two clinical geneticists, three general paediatricians, and a paediatric trainee) to assess current paediatric practice regarding CMA use. Participants were asked about the conditions for which they order CMA tests, their typical practice regarding pre-test counselling, documentation of consent, approach to interpreting and applying CMA results, understanding of the impact of CMA on their patients, and the situations in which they refer on to genetics services. Finally, they identified ways in which the CMA process could be improved for clinicians and patients.

\section{Statistical analysis}

We used simple statistics (frequencies and proportions) to describe the data. Data were exported from REDCap into Excel and then STATA version 13 (Stata, College Station, TX, USA) for statistical analysis.

\section{RESULTS}

Of the 383 active APRN members, 165 (43\%) responded; 78 (47\%) were male. More than half (58\%) of responders worked part-time. Almost two-thirds (62\%) worked in public practice, a third (33\%) worked in private practice alone or in combination with public practice, and $11(6.7 \%)$ worked in a community health setting. Compared with general paediatricians across Australia, responders were more likely to be female, younger, and working part- time (Table 1).

\section{Indications for Testing}

The majority of paediatricians (71-79\%) reported ordering CMA frequently or almost always for intellectual disability, global developmental delay, multiple congenital anomalies, and autism spectrum disorder with intellectual disability (conditions for which there is a rebate on the Medicare Benefit Schedule), with a quarter of paediatricians (21-29\%) rarely or sometimes requesting CMA for these conditions. Less than half of paediatricians reported requesting CMA for autism spectrum disorder with normal range IQ, despite this carrying an MBS rebate. Paediatricians were considerably less likely to order CMA for conditions excluded from the MBS for CMA; the exception to this was dysmorphism, for which $74 \%$ of paediatricians reported that they order CMA frequently or almost always (Table 2).

\section{Consent Process}

When consenting patients for CMA, less than half of respondents reported using consent forms or fact sheets, obtaining written consent, or documenting verbal consent. There was considerable variability 
amongst respondents regarding the topics they typically discuss in pre-test counselling. Paediatricians reported greatest consistency in discussing the potential for CMA results to be uncertain or pathogenic, with $77-84 \%$ of respondents reporting this. Other topics were less routinely discussed, especially implications for family members, life insurance, and the potential to detect non-paternity, non-maternity and consanguinity (Table 3 ).

\section{Interpreting and Applying Results}

$77 \%$ of paediatricians reported needing assistance to interpret a CMA report sometimes, frequently or almost always. In $82 \%$ of cases that assistance involved clinical genetics services, either via referring the patient to genetics (46\%), or contacting a clinical geneticist (36\%).

Paediatricians were more likely to refer to genetics if the CMA result was pathogenic ('Frequently' or 'Almost Always' 80\%) than if it had uncertain significance ('Frequently' or 'Almost Always' 39\%). Most commonly, respondents referred to genetics for advice with interpreting results and applying them to a patient and family ('Frequently' or 'Almost Always' $76-82 \%$ ). We found low rates of referral to clinical genetics services when the mother was currently pregnant ('Frequently' or 'Almost Always' 35\%).

\section{Impact on Patient Management}

Most paediatricians order CMA to establish a diagnosis (85\%) and inform family planning advice (76\%). Only $45 \%$ of paediatricians usually order CMA to assist in their patients' management. $93 \%$ of paediatricians reported that CMA testing only rarely or sometimes changes their management of a child. When a CMA result does change management, this was identified to be through guiding reproductive choices $(69 \%)$, guiding management of a child with a known CNV (58\%), reducing further investigations (57\%), and providing families with a support network (56\%).

\section{Improving the CMA Process}

With regards to improving the CMA process for themselves and their patients, $69 \%$ of paediatricians supported having an available fact sheet for families, and 67\% supported having a standardised consent form. Half felt the CMA process could be improved by having better access to genetics services $(49 \%)$, or by standardised reporting from laboratories $(48 \%)$.

\section{DISCUSSION}

This is the first Australian study to describe paediatricians' practice regarding CMA. Our data demonstrate considerable variation in paediatricians' practices, in relation to conditions for which CMA is requested, the approach to consent and the interpretation and application of results. 
CMA is well-established as a first-line investigation for for autism spectrum disorder, developmental delay, intellectual disability and multiple congenital anomalies. While we found that the majority of Australian paediatricians order CMA routinely for these indications, this practice is far from universal. We recommend that CMA testing should be universally offered to patients with one of these conditions, accepting that not all families may wish to proceed with genetic testing.

In our study, almost half of paediatricians reported that CMA results rarely alter patient management. In a comparable patient population (paediatric patients with autism spectrum disorder/intellectual disability/multiple congenital anomalies), a study of 194 American patients showed pathogenic CNV led to a change in clinical action in $54 \%$ of cases, and a variant of probable pathogenicity led a change in clinical action in $34 \%$ of cases. ${ }^{1217}$ The potential for CMA to affect a child's management in the short and long term, and the impact upon relatives, has been well described elsewhere. ${ }^{18,1913,14}$ Even in the absence of specific management changes, identifying a chromosomal abnormality can alter patient management ${ }^{1520}$ by obviating the need for further diagnostic investigations, informing prognosis, directing the family to a support network, and providing information on the chance of recurrence of the condition risks for family members. Our result suggests an under-appreciation by Australian paediatricians of the potential of CMA to affect patient management.

We found considerable variation in the issues typically discussed by Australian paediatricians when consenting patients and their families. In pre-test counselling, most paediatricians reported discussing the basic issues of CMA (such as the potential of finding a pathogenic change, an uncertain result, or an incidental finding). However, more complex issues are often not raised, such as the impact on family members, family planning and life insurance. Even less commonly do paediatricians discuss the potential for CMA to detect non-paternity, non-maternity or, in the case of a SNP array platform being used, parental consanguinity.

This result is consistent with a study of American paediatric clinicians, which found that many paediatricians did not consider it pertinent to discuss the potential for CMA to reveal information concerning biological parentage or predisposition to late-onset disease. ${ }^{1621}$ However, it falls significantly short of best practice. CMA results can generate significant medical and ethical challenges for clinicians, patients and families. A CMA result may have life-long and wide-ranging impacts upon a child. The pathogenicity of CNV is open to re-interpretation, as knowledge correlating phenotypes and genotypes expands. ${ }^{722}$ Therefore, CMA testing should be preceded by a comprehensive discussion of the potential results and implications. We present recommendations for best practice in pre-test counselling (Box 1).

Fact sheets and standardised consent forms could be used to guide these discussions and assist families to make an informed decision, however we found poor uptake of these currently. This mirrors a study of New Zealand paediatricians. ${ }^{1723}$ Fact sheets are important for informed consent: 
visual material facilitates families' comprehension, and good communication can reduce their anxiety and uncertainty when receiving CMA results. ${ }^{1624}$ There are a number of web-resources available (Box 2 ); we suggest their routine adoption in pre-test counselling.

Our results showed high rates of referral by paediatricians to genetics services following CMA testing, especially for pathogenic CNVs. This suggests clinical genetics services are integral to paediatricians' use of CMA, carrying implications for workforce planning and service provision for clinical genetics. When viewed with our other findings regarding variability in ordering CMA and variability in consenting families, it also suggests that paediatricians may benefit from more training in the field of genetic medicine. We suggest the following flow-chart for paediatricians when considering how to respond to a CMA result (Figure 1), We and make recommendations about when paediatricians should refer to clinical genetics services (Box 3 ).

Our study has some limitations. The response rate was modest at $43 \%$, reflecting the difficulty in accessing busy paediatricians, and recall bias that may have been present due to paediatrician selfreport. Our respondents are members of a research network which may bias the sample towards those who are up-to-date. Furthermore, there is a lack of clarity in the literature regarding CMA and developmental delay. Much of the genetics literature and the Medicare Benefits Schedule refers to 'developmental delay'. We have interpreted this to mean global developmental delay. In our study, we asked paediatricians about their practice with regards to global developmental delay and speech delay, but not other isolated delays.

Our study raises important issues about how paediatric practice could be improved for CMA testing, with a degree of extrapolation possible for other genetic technologies, particularly Next Generation Sequencing (NGS). While CMA and NGS use different technologies, there is a significant crossover in the issues which arise from their clinical implementation, ${ }^{8,1425,26}$ such as the challenge of informed consent, ambiguities generated by variants of uncertain significance, the potential for incidental findings, and the ramifications for relatives and family planning. We can expect these issues to be amplified in NGS, as this technology will generate much greater numbers of incidental findings and variants of uncertain significance and incidental findings. ${ }^{9,19,2027,28,29}$ Our study demonstrated that these issues are problematic for paediatricians with regard to CMA testing. Up-skilling paediatricians in CMA testing will provide them with useful skills as they prepare to navigate the more complex world of NGS.

Moreover, CMA is a technology which will remain an important part of paediatric clinical practice for some time to come. ${ }^{930}$ CMA remains the most appropriate technology to detect copy number variants, ${ }^{2131}$ has a lower rate of incidental findings and findings of uncertain significance, ${ }^{2032}$ and, with a Medicare rebate for a number of conditions, is an affordable technology with a relatively high 
diagnostic yield. With appropriate upskilling, it could be an important diagnostic test in the paediatrician's tool-kit.

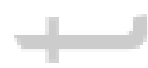

\section{CONCLUSION}

Considerable variation in practice amongst Australian paediatricians exists for the ordering, consent, interpretation and application of CMA. There is a need for clear guidelines to guide the optimal use and application of CMA testing. CMA will remain an important diagnostic tool for some years, and the complexities inherent to CMA will be amplified in NGS.

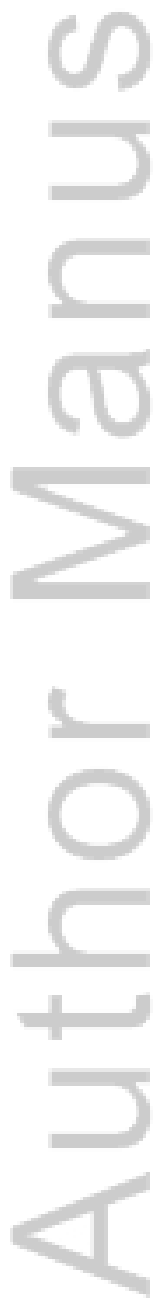

This article is protected by copyright. All rights reserved. 


\section{References}

1. Australian Government, Department of Health Services, Australian Government.. Medicare Australia Statistics. Requested Medicare items processed from July 2015 to June 2016 Available from:

http://medicarestatistics.humanservices.gov.au/statistics/do.jsp?_PROGRAM=\%2Fstatistics\%2Fmbs_i tem_standard_report\&DRILL=ag\&group $=73292 \& V A R=$ services\&STAT $=$ count\&RPT_FMT=by+state\&PT YPE=finyear\&START_DT=201507\&END_DT=201606http://medicarestatistics. humanservices.gov.au/st atistics/do.jsp?_PROGRAM=\%2Fstatistics\%2Fmbs_item_standard_report\&DRILL=ag\&group $=73292 \& \mathrm{~V}$ $A R=$ services\&STAT $=$ count\&RPT_FMT $=$ by+state\&PTYPE=finyear\&START_DT $=201507 \& E N D \_D T=201606$ [Accessed 14 October 2016]

2. Miller DT, Adam MP, Adadhy S et al. Consensus statement: chromosomal microarray is a first-tier clinical diagnostic test for individuals with adevelopmental disabilities or congenital anomalies. Am. J. Hum. Genet. 2010; 86: 749-64

3. Miller et al 2010

4.3. Palmer E, Peters G, Mowat D. Chromosome microarray in Australia: A guide for paediatricians. J. Paediatr. Child Health 2012; 48: E59-E67

5.4. Kharbanda M, Tolmie J, Joss S. How to use... microarray comparative genomic hybridisation to investigate developmental disorders. Arch. Dis. Child Educ. Pract. Ed. 2015; 100: 24-29

6. Palmer et al 2012

7. Kharbanda et al 2015

8.5. Richards S, Aziz N, Bale S et al. Standards and guidelines for the interpretation of sequence variants: a joint consensus recommendation of the American College of Medical Genetics and Genomics and the Association for Molecular Pathology. Genet. Med. 2015; 17: 405-424

9.6. Human Genetics Society of Australasia. Guideline: Best Practice Guidelines for

Chromosomal Microarray for Australian Laboratories,. December 2015. Available from: https://www.hgsa.org.au/documents/item/6911https://www.hgsa.org.au/documents/item/6911 [Accessed 15 June 2016]

10.7 .

Rehm H, Berg J, Brooks L et al. Clingen - The Clinical

Genome Resource. New Engl. J. Med. 2015; 372: 2235-42

11.8. Bruno D, Beddow R, Caramins M et al. Interpreting clinical microarray genomic data in 2012: What have we learnt and what challenges remain? Current Topics in Genetics 2012;

5

12. Palmer et al 2012

13.9. Schnekenberg RP, Nemeth AH. Next-generation sequencing in childhood disorders. Arch. Dis. Child. 2014; 99: 284-291

14. Bruno et al 2012

Comment [EEP1]: Still requiring some editing

Formatted: Font: Italic

Formatted: Default Paragraph Font, Font: (Default) + Body (Calibri), $10 \mathrm{pt}$

Formatted: Default Paragraph Font, Font: (Default) +Body (Calibri), 10 pt

Formatted: Font: Italic

Formatted: Font: Italic

Formatted: Font: Italic

Formatted: Default Paragraph Font, Font: (Default) + Body (Calibri), $10 \mathrm{pt}$

Formatted: Default Paragraph Font, Font: (Default) + Body (Calibri), 10 pt

Formatted: Font: Italic

Formatted: Font: Italic 
15.10. Hiscock H, Efron D, Wasserman R et al. Power to the paediatricians: the Australian Paediatric Research Network is born. J. Paediatr. Child Health 2012; 48: 6-9

16.11. Harris P, Taylor R, Thielke R et al. Research electronic data capture (REDCap) - A metadata-driven methodology and workflow process for providing translational research informatics support. J. Biomed. Inform. 2009; 42(2): 377-81.

17.12. Coulter M, Miller D, Harris D et al. Chromosomal microarray testing influences medical management. Genet. Med. 2011; 13: 770-776.

18.13 . Australian

Government. National Health and Medical Research Council. Medical Genetic Testing: information for health professionals. April 2010. Available from:

www.nhmrc.gov.au/guidelines-publications/e99www.nhmrc.gov.au/guidelines-publications/e99

[Accessed 15 July 2016]

19.14. Riggs E, Wain K, Riethmaier D et al. Chromosomal microarray impacts clinical management. Clin. Genet. 2014; 85: 147-153

20.15. Biesecker L, Biesecker B. An approach to pediatric exome and genome sequencing. Curr. Opin.. Pediatr. 2014; 26: 639-45

21.16. Reiff M, Ross K, Mulchandani S et al. Physicians' perspectives on the uncertainties and implications of chromosomal microarray testing of children and families. Clin. Genet. 2013; 83: 23-30

22. Rehm et al 2015

23.17. Godfrey E, Clark P. Developing standards for chromosomal microarray testing counselling in paediatrics. Acta Paediatrica 2014; 103: 574-77

24.18. Reiff et al 2012 M, Bernhardt B, Mulchandani S et al. "What does it mean?":

Uncertainties in understanding results of chromosomal microarray testing. Genet. Med. 2012;

14: $250-258$

25. Riggs et al 2014

26. Bruno et al 2012

27. Schnekenberg et al 2014

28.19. Abdul-Karim R, Berkman B, Wendler D et al. Disclosure of incidental findings from next-generation sequencing in paediatric genomic research. Pediatrics 2013; 131: $564-$ 571

29.20. Amor D. Future of whole genome sequencing. J. Paediatr. Child Health 2015; 51:

251-254

30. Schnekenberg et al 2014

31.21. Need A, Shashi V, Hitomi Y et al. Clinical application of exome sequencing in undiagnosed genetic conditions. J. Med. Genet 2012; 49: 353-361

32. Amor D 2015 


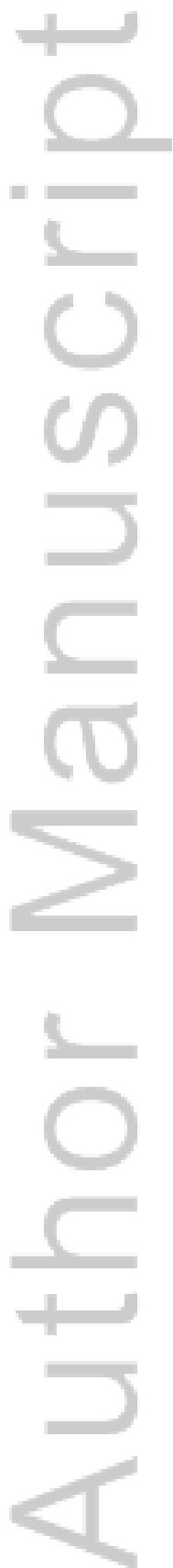

This article is protected by copyright. All rights reserved. 
Table 1: Characteristics of APRN active members (survey responders and non-responders) compared to all Australian paediatricians

\begin{tabular}{|c|c|c|c|c|}
\hline$\frac{1}{4+9}$ & $\begin{array}{c}\text { APRN survey } \\
\text { responders } \\
(\mathrm{n}=165) \\
\mathrm{n} \quad(\%)\end{array}$ & $\begin{array}{c}\text { APRN survey } \\
\text { non-responders } \\
(\mathrm{n}=218) \\
\mathrm{n} \quad(\%)\end{array}$ & \multicolumn{2}{|c|}{$\begin{array}{c}\text { All Australian } \\
\text { paediatricians } \\
(\mathrm{n}=1442) \\
\mathrm{n} \quad(\%)\end{array}$} \\
\hline \multicolumn{5}{|l|}{ Sex } \\
\hline Male & 78 (47.3) & $103(47.2)$ & 701 & $(48.6)$ \\
\hline \multicolumn{5}{|l|}{ Age (years) } \\
\hline$<44$ & 73 (44.2) & $94 \quad(43.1)$ & 440 & $(30.5)$ \\
\hline $45-54$ & $51 \quad(30.9)$ & 68 (31.2) & 463 & $(32.1)$ \\
\hline $55-64$ & 27 (16.4) & 39 (17.9) & 342 & $(23.7)$ \\
\hline $65+$ & $12(7.3)$ & $11(5.0)$ & 146 & $(10.1)$ \\
\hline \multicolumn{5}{|l|}{ Working hours* } \\
\hline Part-time & $96 \quad(58.2)$ & $112(51.4)$ & 373 & $(25.9)$ \\
\hline Full-time & $69(41.8)$ & $48 \quad(22.0)$ & 837 & $(58.0)$ \\
\hline \multicolumn{5}{|l|}{ Practice setting^ } \\
\hline Academic post & $14(8.5)$ & $30(13.8)$ & & - \\
\hline Private practice & $54(32.7)$ & $58 \quad(26.6)$ & & - \\
\hline $\begin{array}{l}\text { Public Outpatients } \\
\text { Community Health }\end{array}$ & $102(61.8)$ & $125(57.3)$ & & - \\
\hline Centre & $11 \quad(6.7)$ & $17(7.8)$ & & - \\
\hline \multicolumn{5}{|l|}{ Practice location* } \\
\hline Metropolitan & 115 (69.7) & $109(50.0)$ & 1182 & $(82.0)$ \\
\hline Regional/Rural & 49 (29.7) & $43 \quad(19.7)$ & 216 & $(15.0)$ \\
\hline
\end{tabular}

*Data not available for all non-responders.

$\wedge^{\wedge}$ Data not mutually exclusive 
Table 2: Indications for CMA testing

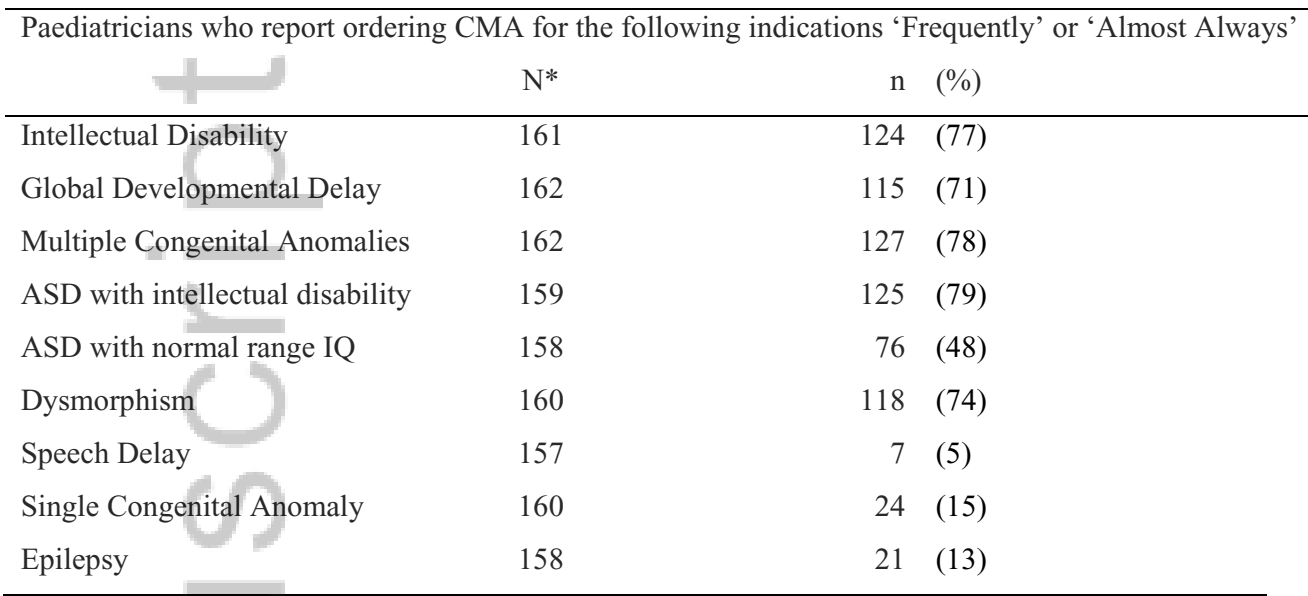

*Total number of doctors who responded to this question 
Table 3: Paediatricians' self-report on their practice for consent for CMA testing

Paediatricians who report engaging in the following practices 'Frequently' or 'Almost Always'

\begin{tabular}{llll} 
& $\mathrm{N}^{*}$ & $\mathrm{n}$ & $(\%)$ \\
\hline Use a fact sheet & 155 & 43 & $(28)$ \\
Use a standardised consent form & 157 & 21 & $(13)$ \\
Document verbal consent & 158 & 75 & $(47)$ \\
Obtain written consent & 155 & 18 & $(12)$
\end{tabular}

Paediatricians who report discussing the following topics typically

\begin{tabular}{llrl} 
& $\mathrm{N}^{*}$ & $\mathrm{n}$ & $(\%)$ \\
\hline Likelihood of a pathogenic CNV & 166 & 127 & $(77)$ \\
Likelihood of an uncertain result & 166 & 139 & $(84)$ \\
Likelihood of an incidental finding & 166 & 127 & $(77)$ \\
Likelihood result will change treatment & 166 & 68 & $(41)$ \\
Potential need to test family members & 166 & 115 & $(69)$ \\
Implications for health/life insurance & 166 & 37 & $(22)$ \\
Implications for family members & 166 & 88 & $(53)$ \\
Potential to detect non-paternity / non-maternity / & 166 & 18 & $(11)$ \\
consanguinity & & & \\
Implications for family planning & 166 & 103 & $(62)$ \\
\hline
\end{tabular}

*Total number of doctors who responded to this question

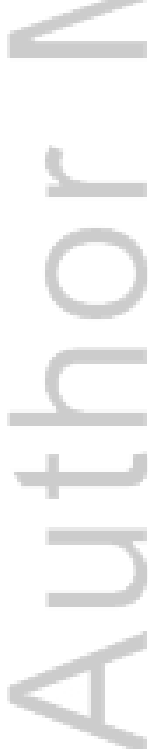


Box 1. Informed Consent for CMA - What do patients and families need to know?

With acknowledgement to Sydney Children's Hospital

- There are multiple potential results: no CNV, benign CNV, pathogenic CNV, CNV of uncertain significance and CNV of unknown significance*

- An uncertain result is not infrequent - up to $20 \%$ of studies

- Some genetic abnormalities cannot be identified by $\mathrm{CMA}^{\wedge}$

- Testing may reveal incidental findings: eg a CNV which predisposes to an adult-onset condition, for which treatment may or may not be available

- Testing may reveal non-paternity/non-maternity of a presumed parent

- Testing may suggest a closer parental relationship than is known or suspected

- Family members may need to be tested, and may be affected by results

- Testing will not impact health insurance but may affect applications for life insurance and other forms of insurance

- DNA will be stored for potential reanalysis in the future but may not remain in a suitable state for testing

- Interpretation of test results may change in the future

- If a CNV is found, CMA result may need to be confirmed by repeat array or alternative test due to potential false positives

- Clinical Genetics referral may be needed

*terminology differs between laboratories

${ }^{\wedge}$ mosaicism, balanced translocations, sequence variants and triplet repeat disorders such as fragile $\mathrm{X}$ syndrome 


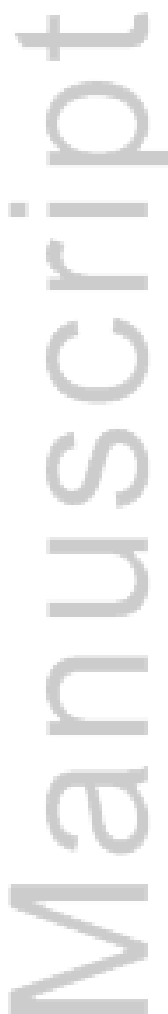

Box 2: Resources for Paediatricians and Families

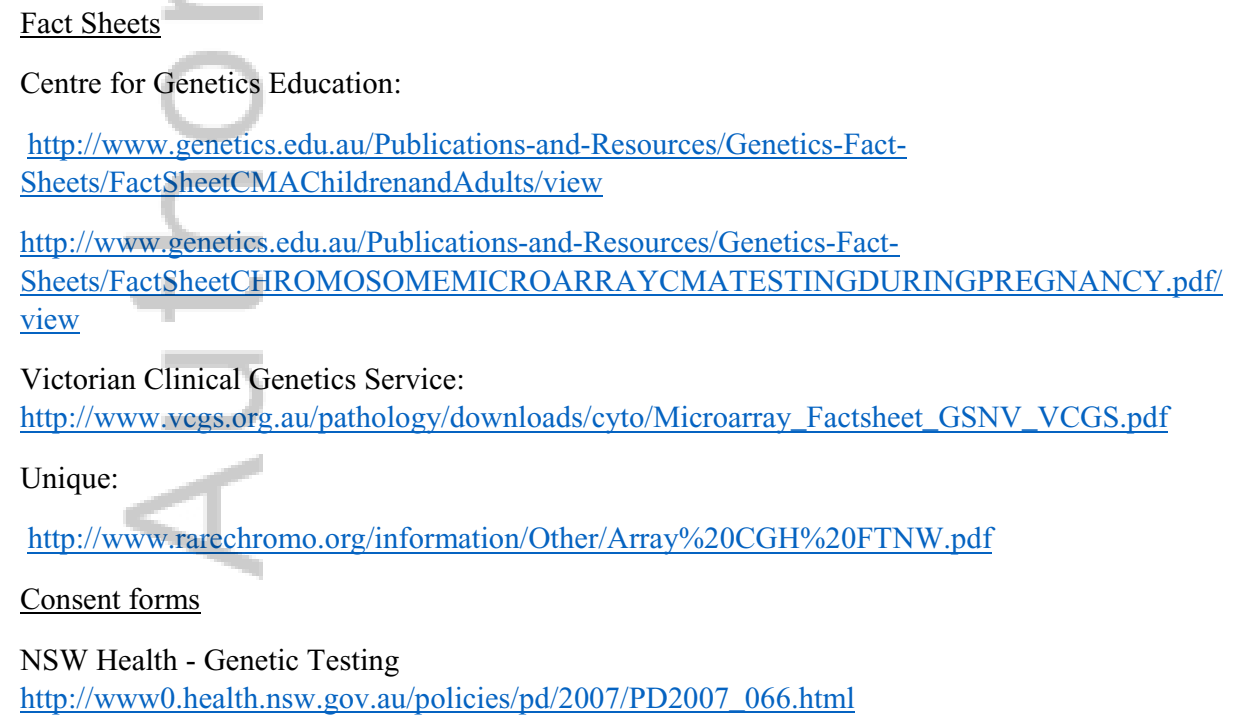




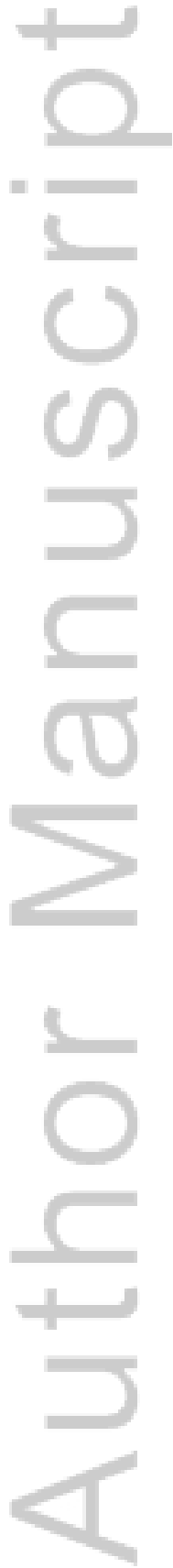

This article is protected by copyright. All rights reserved. 
Box 3: When should paediatricians consider consulting or refer referring to Clinical Genetics

- Uncertainty interpreting a laboratory report

- Uncertainty re significance of CNV - especially for variants of uncertain or unknown significance, and variants on the $\mathrm{X}$ chromosome

- Uncertainty re need to test relatives - especially for parent with neurocognitive phenotype

- If CMA is normal (ie, no CNV or benign CNV) but genetic condition is still suspected and/or family concerned re recurrence in future pregnancies* - May need further genetic testing e.g. targeted FISH / NGS

- Prior to genetic testing if mother is pregnant

- Family require more detailed information re: recurrence risk / prognosis

- Long continuous stretch of Homozygosityhomozygosity: Are there concerns re child protection or a specific recessive condition?

- Yes $\rightarrow$ refer to Clinical Genetics/ Child protection services.

- No $\rightarrow$ no further ix/referral needed

*CMA may not detect mosaicism, balanced translocations, sequence variants and triplet repeat disorders such as fragile $\mathrm{X}$ syndrome

Services? 


\section{University Library}

\section{- M M N E R VA A gateway to Melbourne's research publications}

Minerva Access is the Institutional Repository of The University of Melbourne

Author/s:

McKay, V;Efron, D;Palmer, EE;White, SM;Pearson, C;Danchin, M

Title:

Current use of chromosomal microarray by Australian paediatricians and implications for the implementation of next generation sequencing

Date:

2017-07-01

Citation:

McKay, V., Efron, D., Palmer, E. E., White, S. M., Pearson, C. \& Danchin, M. (2017). Current use of chromosomal microarray by Australian paediatricians and implications for the implementation of next generation sequencing. JOURNAL OF PAEDIATRICS AND CHILD HEALTH, 53 (7), pp.650-656. https://doi.org/10.1111/jpc.13523.

Persistent Link:

http://hdl.handle.net/11343/292821 